reinforcement in $S_{1}$ and $S_{2}$ which correlate with changes in the response rate in $S_{1}$ or $S_{2}$ or both. This position is not incompatible with Terrace's (1968) results if one assumes that the procedures used to reduce the response rate in $S_{2}$ (i.e., punishment and a DRL reinforcement schedule) affected the "quality" of reinforcement and thereby effectively reduced the reinforcement in $S_{2}$.

\section{REFERENCES}

Lyons, J., \& Klipec, W. D. Color mixing with Kodak Wratten filters. Journal of the Experimental Analysis of Behavior, $1971,15,232$.

Terrace, H. S. Stimulus control. In W. K. Honig (Ed.), Operant behavior areas of research and application. 1966.
Terrace, H. S. Discrimination learning, the peak-shift and behavioral contrast. Journal of the Experimental Analysis of Behavior. 1968.11. 727-741.

Terrace, H. S. Discrimination learning and the concept of inhibition. In R. A. Boakes and M. S. Halliday (Eds.), Learning and inhibition. New York: Academic Press, 1973.

\section{NOTE}

1. These stimuli are thought of as being an ordinal rather than an interval scale and are not considered monochromatic. (cf. Lyons \& Klipec, 1971 for details of the procedures used to produce the wavelengths.)

\title{
The effects of social interaction upon persistence of self-punitive behavior
}

\author{
JEANNE WALKER, SHARON WILLIAMS and R. CHRIS MARTIN \\ University of Missouri, Kansas City, Missouri 64110
}

\begin{abstract}
Four groups of rats were trained to escape shock in a straight runway prior to institution of punishment conditions in an attempt to assess the effect of the presence of another $S$ upon the persistance of self-punitive behavior. All rats first received the usual 35 shock escape training trials. Then, during extinction when no shock was present in the goalbox or startbox, Ss were put into one of four groups: punished, nonpunished, punished with a naive $S$, and punished with another punished $S$. Results showed that punishment produced self-punitive behavior and that the presence of another $S$ decreased the number of trials a punished $S$ would perform. The presence of a naive $S$ had more effect than the presence of a trained $\mathrm{S}$. The results are discussed in terms of generalization decrement, social interaction, and fear.
\end{abstract}

Since the first study which definitely established the self-punitive paradigm with shock escape training (Brown, Martin, \& Morrow, 1964), most of the research in this area has been concerned with establishing the optimum conditions for producing the phenomenon (Martin \& Melvin, 1964; Melvin \& Martin, 1966). (For a review of the literature, see Brown, 1971.) Recently, however, some studies have been done about the methods of inhibiting the phenomenon.

Treatment conditions for stopping self-punitive behavior have consisted of an $18 \mathrm{~min}$ rest interval between acquisition and extinction trials (Martin, 1969), the administration of chlorpromazine (Martin, Deemer, \& McArdle, 1971), electroconvulsive shock treatments (Stofiel \& Martin, 1966) and both implosive therapy and desensitization therapy (Martin \& Willoughby, 1973). All of these treatment conditions have been successful, in varying degrees, in inhibiting self-punitive behavior. In all of these studies, the Es have had as their aim the reduction of fear. The results of these studies supported the Mowrer-Brown fear hypothesis as the most viable theoretical explanation of the phenomenon.

Recently there have been several studies of the effects of social interaction as a method of reducing fear in rats. Latané (1968) found that rats tested singly and in pairs showed less fear (as defined by freezing) of a strange place when in pairs and that gregariousness increased and fear decreased over time. A followup study by Latané and Glass (1969) confirmed these results. Davitz and Mason (1955) found that the presence of another rat could reduce the fear response (as defined by freezing) of a fearful rat which had received shock paired with a light. Less fear was exhibited when another fearful rat was present and least fear when a nonfearful rat was present. Similarly, Marina and Bauermeister (1974) found that the presence of another rat reduced fear in a one-way hurdle jumping situation where the $\mathrm{S}$ had been trained to avoid shock paired with a light and tone.

Since the presence of another rat can reduce fear as defined by freezing and fear as defined by hurdle jumping, then it should also reduce fear as defined by running as it occurs in self-punitive behavior. Therefore, rats which had been trained to escape shock were tested in four conditions: alone in the punished conditions; alone in the nonpunished condition; paired with another similarly trained rat in the punished 


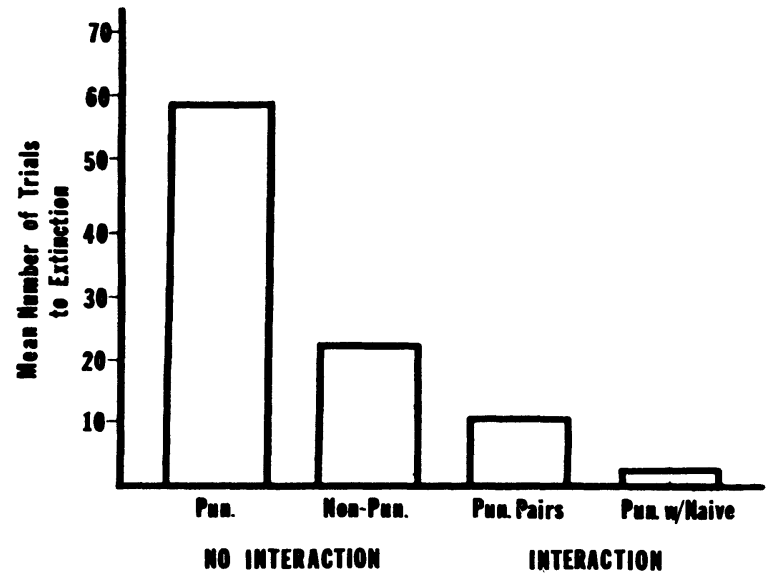

Fig. 1. Mean number of trials to extinction for the four groups.

condition; or paired with a naive rat in the punished condition.

\section{METHOD}

\section{Subjects}

Eighty-two Holtzman Derived male rats, 90 to 120 days old and weighing approximately $300 \mathrm{~g}$, were used. They were fed lab chow and water ad lib. Food was removed $24 \mathrm{~h}$ before the experiment.

\section{Apparatus \\ The apparatus was a straight runway divided into a startbox $(30.48 \times 30.48 \times 20.32 \mathrm{~cm})$, alley $(182.88 \times 30.48 \times 20.32 \mathrm{~cm})$ and a goalbox $(30.48 \times 30.48 \times 0.48 \mathrm{~cm})$, by two guillotine doors. The startbox and alley were painted white and had a grid floor of $.64 \mathrm{~cm}$ steel rods, $1.27 \mathrm{~cm}$ apart, through which a shock ( $2 \mathrm{~mA})$ could be delivered from a Lehigh Valley Constant Current shock source. The tops of the startbox and alley were hinged Plexiglas. The goalbox had a wooden floor and a hinged wooden top and was painted black. Photocells located $15.24 \mathrm{~cm}$ from each end of the alley were used to measure startbox latency and alley speed to the nearest $.01 \mathrm{sec}$. Startbox latency was measured from the time the guillotine door of the startbox was raised until the time the $S$ passed the first photocell. Alley time was measured from the time the $S$ passed between the first and second photocells.}

\section{Procedure}

Acquisition. Ss were assigned to one of three groups: punished, nonpunished or naive. Punished and nonpunished rats received 35 shock escape training trials; the naive rats were not trained to run. All trained Ss spent $30 \mathrm{sec}$ intertrial interval in the goalbox. Twenty of the punished Ss were trained as pairs and received alternating training trials. In addition to the regular 30 -sec intertrial interval, Ss in the punished pair group spent $30 \mathrm{sec}$ in a holding cage which was a replica of the goalbox.

After acquisition, Ss were assigned to one of four conditions: punished (15 Ss), nonpunished (15 Ss), punished pairs $(20 \mathrm{Ss})$, or punished-naive pairs (32 Ss).

Extinction. Punished Ss received $45.72 \mathrm{~cm}$ of shock directly outside the startbox during extinction trials; nonpunished Ss received no shock. These Ss ran alone in accordance with the procedure for establishing the self-punitive paradigm.

The punished pairs were placed in the startbox together immediately after receiving the alternating training trials. They spent their intertrial interval in both the goalbox and the intermediate holding box, as they had during training, in order to maintain the continuity of their visual and auditory cues.

The punished-naive pairs were also run simultaneously; a naive $S$ being placed with a punished $S$ immediately after its acquisition trials. In this case the intermediate holding box was not used during acquisition and was therefore unnecessary during extinction trials.

Both paired groups received $45.72 \mathrm{~cm}$ of shock directly outside the startbox.

Records of startbox latency and alley speed were kept during acquisition and extinction trials to the nearest $.01 \mathrm{sec}$. Extinction was said to have occurred when the $S$ had remained outside the goalbox for longer than $60 \mathrm{sec}$ after the startbox door was opened. In the paired condition, it was necessary for both Ss to remain outside the goalbox for longer than $60 \mathrm{sec}$ to meet the extinction criteria.

\section{RESULTS}

Mean number of responses to extinction for each group is shown in Fig. 1. It may be seen that the punished group was most resistant to extinction, followed by the nonpunished group, the punished pairs, and the punished-naive pairs. It may also be seen that the two groups which had no social interaction showed greater resistance to extinction than the two groups which did have social interaction.

An analysis of variance showed a significant punishment effect $(\mathrm{F}=41.64, \mathrm{df}=3 / 62, \mathrm{p}<.01)$.

$T$ tests for simple effects showed that the difference between the punished group and the nonpunished group was statistically significant $(\mathrm{t}=6.36, \mathrm{df}=28, \mathrm{p}<.001)$, the difference between the punished group and the punished pairs was significant $(\mathrm{t}=8.58, \mathrm{df}=33$, $\mathrm{p}<.001)$, the difference between the punished group and the punished-naive pairs was significant $(t=9.87$, $\mathrm{df}=29, \mathrm{p}<.001)$ and the difference between the punished pairs and the punished-naive pairs was significant $(\mathrm{t}=1.72, \mathrm{df}=36, \mathrm{p}<.05)$.

Figure 2 depicts the mean running speed over number of trials for the four groups. An analysis of variance of these data showed a significant punishment effect $(\mathrm{F}=31.05, \mathrm{df}=3 / 62, \mathrm{p}<.001$, found trials to be significant $(F=28.12$, df $=19 / 1158, \mathrm{p}<.001)$ and found Trials by Punishment significant $(F=6.15$, $\mathrm{df}=57 / 1158, \mathrm{p}<.01)$. T tests for simple effects showed that the difference between the punished vs the nonpunished groups was statistically significant $(t=7.97, d f=598, p<.05)$, the difference between the punished group vs the punished-naive pairs was significant $(t=9.03, d f=618, p<.05)$ and the difference between the punished groups vs the punished pairs was significant $(t=7.29, \mathrm{df}=698, \mathrm{p}<.05)$. The differences between the nonpunished group vs the punished-naive pairs, the nonpunished group vs the punished pairs and the punished-naive pairs vs the punished pairs were found not to be significant. 
Fig. 2. Mean speed in centimeters per second across blocks of five trials with blocks 1.7 representing acquisition and blocks 8-27 representing extinction.

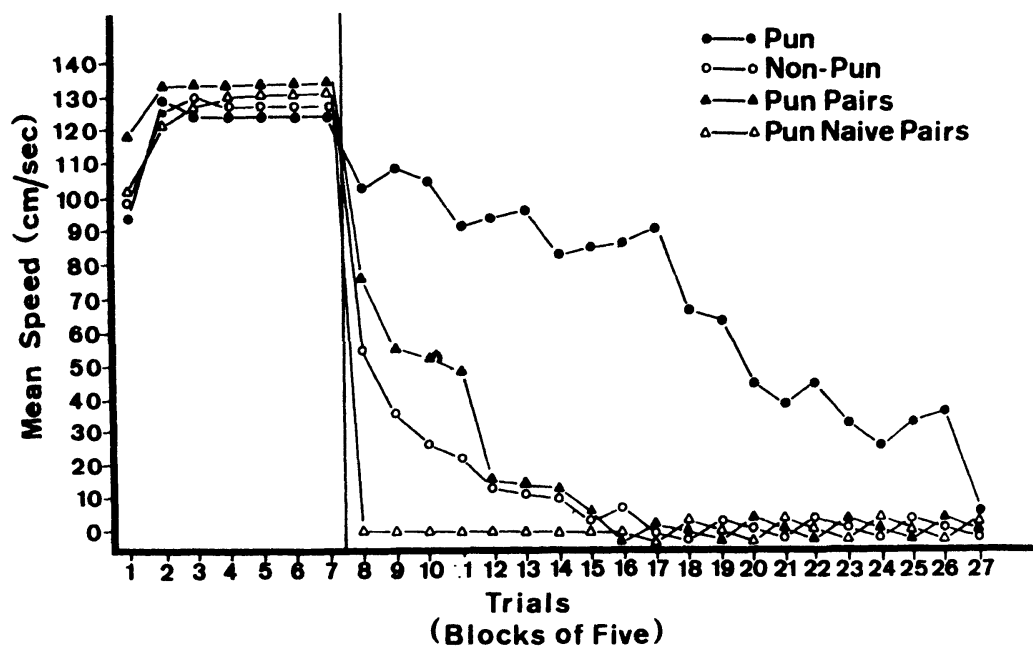

\section{DISCUSSION}

The results showed the occurrence of the basic self-punitive phenomenon and a drastic reduction in the resistance to extinction of those Ss who had social interaction during extinction trials. Presence of a punished rat decreases self-punitive behavior in the same direction as the presence of a naive rat, but to a lesser degree.

One explanation for this inhibition of an established behavior pattern is that the introduction of another rat in the startbox may weaken the power of the stimulus complex capable of eliciting fear.

Coupled with this possibility is the fact that rats have been found to be very gregarious (Latané, 1968) and tend to stay very close together in a free choice situation. Under normal circumstances, rats react to fear producing situations by freezing so that one might hypothesize that the naive rat would react to his exposure to the unfamiliar startbox by freezing. The punished rat would, therefore, be placed into conflict between running, as a learned fear response, or remaining with the other rat and exhibiting the more natural fear response of freezing. This hypothesis would also account for the fact that punished pairs ran longer than punished-naive pairs. Since both rats in the punished pairs had been trained to respond to fear by running, more trials were necessary to inhibit the behavior than in the punished-naive pairs. Their natural gregariousness and investigatory behavior caused a slowing in alley speed and may have caused a reduction in emotionality. As soon as one member of a pair stopped running, the other member extinguished within a maximum of four trials (with one exception of 24 trials).

Further study in this area might include application of these findings to situations involving humans in fear or anxiety producing situations. Measurements of anxiety levels taken when the $\mathrm{S}$ was alone could be compared with measurements taken when in the presence of a friend.

\section{REFERENCES}

Brown. J. S. Factors affecting self-nunitive locomotor behavior. In B. A. Campbell and R. M. Church (Eds.) Punishment and In B. A. Campior. New Y ork: A ppleton-Century-Crofts, 1971.

Brown, J. S., Martin, R. C., \& Morrow, M. W. Self-punitive behavior in the rat: Facilitative effects of punishment on resistance to extinction. Journal of Comparative \& Physiological Psychology, 1964, 57, 127-133.

Davitz, J. R., \& Mason, D. J. Socially facilitated reduction of a fear response in rats. Journal of Comparative and Physiological Psychology, 1955, 48, 148-151.

Latane, B. Gregariousness and fear in lab rats. Journal of Experimental Social Psychology, 1968, 5, 61-69.

Latane, B. \& Glass, D. C. Social and non-social attraction in rats. Journal of personality and Social Psychology, 1969, 9, 142-146.

Marina, J. F. \& Bauermeister, J. J. Socially facilitated extinction of a conditioned avoidance response. Bulletin of the Psychonomic Society, 1974, 3(3A), 161-163.

Martin, R. C. Self-punitive behavior: One way to stop it. Psychonomic Science, 1969, 14(1), 25-26.

Martin, R. C., Deemer, B. L., \& McArdle, N. The effects of chlorpromazine on self-punitive behavior. Psychonomic Science, 1971, 23, 339-340.

Martin, R. C., \& Melvin, K. B. Fear responses of bobwhite quail (Colinus virginianus) to a model and a live redtailed hawk (Buteo janaicensis). Psychologische Forschung, 1964, 27, 323-336.

Martin, R. C., \& Willoughby, L. Desensitization vs implosive therapy on self-punitive behavior. Paper presented at Psychonomic Society Convention in St. Louis, Missouri, 1973.

Melvin, K. B., \& Martin, R. C. Facilitative effects of two modes of punishment on resistance to extinction. Journal of Comparative \& Physiological Psychology, 1966, 62, 491-494.

Stofiel, P. \& Martin, R. C. The effects of electro-convulsive shock upon self-punitive behavior. Paper presented to the Southeastern Psychological Association, Atlanta, Georgia, 1972 . 